WEDNESDAY, 12 JUNE 2019

\section{Rehabilitation; opening Pandora's Box}

\section{OP0079-HPR NON-PHARMACOLOGICAL CARE IN SYSTEMIC SCLEROSIS: OPENING THE BLACK BOX}

Juliane Stöcker ${ }^{1,2.3}$, Julia Spierings ${ }^{4}$, Madelon Vonk ${ }^{1}$, Frank van den Hoogen ${ }^{1,2}$, M. W.G. Nijhuis-van der Sanden ${ }^{1}$, J.B. Staal ${ }^{1,3}$, Ton Satink ${ }^{3}$, C.H.M. van den Ende ${ }^{1,2}$, ARCH. ${ }^{1}$ Radboud University Medical Centre, Nijmegen, Netherlands; ${ }^{2}$ Sint Maartenskliniek, Nijmegen, Netherlands; ${ }^{3}$ HAN University of Applied Sciences, Nijmegen, Netherlands; ${ }^{4}$ University Medical Centre Utrecht, Utrecht, Netherlands

Background: Although health professional (HP) treatments are considered to be a corner stone in the management of systemic sclerosis (SSc), little is known about the referral process to and the content of non-pharmacological care in SSc. Objectives: To describe non-pharmacological care in SSc from the perspective of Dutch HPs, including referral reasons, diagnostic focus, interventions used and alignment in the communication between HPs and rheumatologists.

Methods: Dutch HPs were invited through their SSc patients to complete an anonymous online survey provided by the Dutch ARCH (Arthritis Research and Collaboration Hub) working group. The survey comprised multiple response and open questions covering six topics: sociodemographic questions, referral reasons, diagnostic focus, treatment targets, interventions and the assessment of quality of communication between HPs and rheumatologists based on the Consumer Quality Index (CQI) (rheumatoid arthritis, version 2.0). Referral reasons and treatment targets were examined by means of open questions, and then linked to the ICF (International Classification of Functioning, Disability and Health) following the refined ICF Linking Rules (Cieza, 2016).

Results: A total of $79 \mathrm{HPs}, 65.8 \%$ women $(\mathrm{N}=52)$, with a mean age of 41.2 $(\mathrm{SD}=13.6)$ from 8 different professions completed the survey. Physiotherapists were the largest group represented $(73 \%, \mathrm{~N}=58)$. All in all 133 different referral reasons were reported that yielded 58 different ICF codes, of which $70.7 \%(\mathrm{~N}=$ 41) could be linked to the ICF domain "body structures and functions". The reported interventions focus on body functions and structures, training of daily activities, education and advices and psychosocial interventions (Table 1). The quality of communication between HPs and rheumatologists as perceived by the HPs is shown in Table 2.
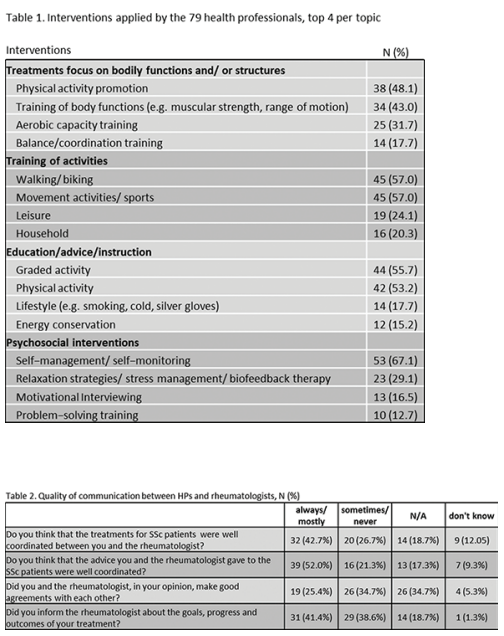

Conclusion: The results of this study show clear discrepancies between referral reasons and applied interventions, visible in the clear focus on body functions and structures on one hand and the broad spectrum of applied interventions on the other hand. It is possible that HPs make a translation of the reasons given for referral to the needs of the individual patient. Viewed from this perspective, it is questionable whether the referrals by the rheumatologists are sufficiently targeted. Further, the results describe a suboptimal communication between rheumatologists and HPs that should be targeted in practice and further research.

\section{REFERENCE:}

[1] Cieza, et al., (2016). Refinements of the ICF Linking Rules to strengthen their potential for establishing comparability of health information. Disability and rehabilitation, 1-10.

Disclosure of Interests: Juliane Stöcker: None declared, Julia Spierings Grant/ research support from: Boehringer Ingelheim, Madelon Vonk Grant/research support from: Madelon Vonk has received unrestricted research funds from Actelion and Therabel, Consultant for: Madelon Vonk was a consultant for Actelion,
Boehringer-Ingelheim, Speakers bureau: Actelion, Boehringer-Ingelheim, Roche, Frank van den Hoogen: None declared, M.W.G. Nijhuis-van der Sanden: None declared, J.B. Staal: None declared, Ton Satink: None declared, C.H.M. van den Ende: None declared

DOI: 10.1136/annrheumdis-2019-eular.4122

WEDNESDAY, 12 JUNE 2019

\section{Osteoporosis}

\begin{tabular}{|l}
\hline OP0080 \\
EFFECT OF DENOSUMAB VERSUS RISEDRONATE ON \\
CORTICAL AND TRABECULAR BONE \\
MICROARCHITECTURE BY HIGH RESOLUTION \\
PERIPHERAL QUANTITATIVE COMPUTED \\
TOMOGRAPHY (HR-PQCT) IN GLUCOCORTICOID- \\
TREATED INDIVIDUALS
\end{tabular}

Piet Geusens ${ }^{1}$, Stefan Goemaere ${ }^{2}$, Nicola Pannacciulli ${ }^{3}$, Nancy Lane ${ }^{4}$ Eric Lespessailles $^{5}$, Osvaldo Messina ${ }^{6}$, Roland Chapurlat ${ }^{7}$, Xiang Yin ${ }^{8}$, Rachel Wagman', Joop van den Bergh ${ }^{1} .{ }^{1}$ Maastricht University, Maastricht, Netherlands; ${ }^{2}$ Ghent University Hospital, Ghent, Belgium; ${ }^{3}$ Amgen Inc., Thousand Oaks, United States of America; ${ }^{4}$ University of California, Davis, United States of America; ${ }^{5}$ University Hospital Orleans, Orleans, France; ${ }^{6}$ Cosme Argerich Hospital, Buenos Aires, Argentina; ${ }^{7}$ Hopital Edouard Herriot, Lyon, France; ${ }^{8}$ Amgen Inc, Thousand Oaks, United States of America; ${ }^{3}$ Amgen Inc., Thousand Oaks, United States of America

Background: In a study of patients initiating or continuing GC, 12 and 24 months gains in lumbar spine and total hip areal bone mineral density (aBMD) were greater with DMAb vs RIS. ${ }^{1,2}$

Objectives: Evaluate the effects of DMAb vs RIS on cortical and trabecular bone. Methods: Phase 3, double-blind, double-dummy, active-controlled study randomised women and men $\geq 18$ years, receiving GC ( $\geq 7.5 \mathrm{mg}$ prednisone daily or equivalent) for $<3$ (GC-initiating [GC-I]) or $\geq 3$ months (GC-continuing [GC-C]), to DMAb $60 \mathrm{mg}$ every 6 months or RIS $5 \mathrm{mg}$ daily for 24 months. Subjects $<50$ years had a history of osteoporosis (OP) fracture. GC-C subjects $\geq 50$ years had lumbar spine, total hip or femoral neck BMD T-score $\leq-2.0$; or T-score $\leq-1.0$ with history of OP fracture. All subjects were to receive daily calcium $(\geq 1000 \mathrm{mg})$ and vitamin $\mathrm{D}(\geq 800 \mathrm{IU})$. In a subset, HR-pQCT scans of the distal radius and distal tibia were performed at baseline and Months 12 and 24. Treatment differences (DMAb-RIS) were estimated using analysis of covariance (ANCOVA)

Results: The substudy enrolled 111 subjects (57 DMAb, 54 RIS). DMAb was associated with significantly greater increases than RIS in cortical thickness, total volumetric BMD (VBMD) and cortical VBMD at the radius and tibia at 12 and 24 months, and in trabecular vBMD at the radius at 12 months and tibia at 24 months (Table). Change in cortical porosity did not differ between DMAb and RIS (Table). Percentage Change From Baseline and Treatment Difference in VBMD and Cortical Microarchitecture

\begin{tabular}{|c|c|c|c|c|c|}
\hline & & \multicolumn{2}{|c|}{ Distal Radius } & \multicolumn{2}{|c|}{ Distal Tibia } \\
\hline & & Month 12 & Month 24 & Month 12 & Month 24 \\
\hline \multirow[t]{3}{*}{ Total vBMD } & DMAb & $1.8(0.7,2.8)$ & $4.1(2.6,5.6)$ & $1.3(0.4,2.2)$ & $2.2(1.2,3.1)$ \\
\hline & RIS & $\begin{array}{c}-1.1(-2.2,- \\
0.1)\end{array}$ & $\begin{array}{c}-1.7(-3.3,- \\
0.1)\end{array}$ & $\begin{array}{c}-0.8(-1.8 \\
0.1)\end{array}$ & $\begin{array}{c}-1.4(-2.4,- \\
0.4)\end{array}$ \\
\hline & DMAb_RIS & $\begin{array}{c}2.9(1.4 \\
4.4) \dagger\end{array}$ & $\begin{array}{c}5.8(3.6 \\
7.9) \dagger\end{array}$ & $\begin{array}{c}2.2(0.9 \\
3.5) \dagger\end{array}$ & $\begin{array}{c}3.6(2.2 \\
5.0) \dagger\end{array}$ \\
\hline \multirow[t]{3}{*}{ Cortical vBMD } & DMAb & $\begin{array}{c}0.2(-0.4 \\
0.8)\end{array}$ & $1.2(0.4,1.9)$ & $\begin{array}{c}0.5(-0.1 \\
1.1)\end{array}$ & $1.0(0.4,1.5)$ \\
\hline & RIS & $\begin{array}{c}-0.7(-1.3,- \\
0.1)\end{array}$ & $\begin{array}{c}-1.4(-2.2,- \\
0.6)\end{array}$ & $\begin{array}{c}-0.7(-1.3,- \\
0.1)\end{array}$ & $\begin{array}{c}-1.3(-1.8,- \\
0.7)\end{array}$ \\
\hline & DMAb—RIS & $\underset{*}{0.9} \underset{*}{(0.1,1.8)}$ & $\begin{array}{c}2.6(1.5 \\
3.6) \dagger\end{array}$ & $\underset{\star}{1.2} \underset{*}{(0.4,2.1)}$ & $\begin{array}{c}2.2(1.4 \\
3.1) \dagger\end{array}$ \\
\hline \multirow[t]{3}{*}{$\begin{array}{l}\text { Trabecular } \\
\text { vBMD }\end{array}$} & DMAb & $2.3(0.2,4.3)$ & $\begin{array}{c}9.4(1.4 \\
17.3)\end{array}$ & $\begin{array}{c}0.8(-0.3 \\
1.8)\end{array}$ & $1.7(0.7,2.8)$ \\
\hline & RIS & $\begin{array}{c}-0.9(-3.0 \\
1.1)\end{array}$ & $\begin{array}{c}-0.7(-9.0 \\
7.6)\end{array}$ & $\begin{array}{c}-0.3(-1.3 \\
0.7)\end{array}$ & $\begin{array}{c}-0.4(-1.5 \\
0.6)\end{array}$ \\
\hline & DMAb_RIS & $\underset{*}{3.2} \underset{*}{(0.3,6.1)}$ & $\begin{array}{c}10.1(-1.4 \\
21.6)\end{array}$ & $\begin{array}{c}1.1(-0.4, \\
2.5)\end{array}$ & $\begin{array}{c}2.1 \\
* \\
*\end{array}$ \\
\hline \multirow[t]{3}{*}{$\begin{array}{l}\text { Cortical } \\
\text { porosity }\end{array}$} & DMAb & $\begin{array}{c}2.3(-2.9, \\
7.5)\end{array}$ & $\begin{array}{c}8.5(1.1, \\
15.9)\end{array}$ & $\begin{array}{c}1.3(-2.5, \\
5.2)\end{array}$ & $\begin{array}{c}3.0(-0.7, \\
6.6)\end{array}$ \\
\hline & RIS & $\begin{array}{c}2.2(-3.1 \\
\quad 7.6)\end{array}$ & $\begin{array}{c}10.2(2.5 \\
18.0)\end{array}$ & $\begin{array}{c}2.0(-1.9 \\
5.9)\end{array}$ & $\begin{array}{c}1.7(-2.1 \\
5.5)\end{array}$ \\
\hline & DMAb_RIS & $\begin{array}{c}0.1(-7.3 \\
7.5)\end{array}$ & $\begin{array}{c}-1.7(-12.4 \\
9.0)\end{array}$ & $\begin{array}{c}-0.7(-6.1 \\
4.8)\end{array}$ & $\begin{array}{c}1.3(-4.0, \\
6.6)\end{array}$ \\
\hline $\begin{array}{l}\text { Cortical } \\
\text { thickness }\end{array}$ & DMAb-RIS & $\begin{array}{c}5.2(2.9 \\
7.4) \dagger\end{array}$ & $\begin{array}{c}8.6(5.4 \\
11.8) \dagger\end{array}$ & $\begin{array}{c}3.5(1.7 \\
5.2) \dagger\end{array}$ & $\begin{array}{c}6.0(3.5 \\
8.5) \dagger\end{array}$ \\
\hline
\end{tabular}

Reported as LS mean (95\% Cl); p-value based on ANCOVA that included treatment, baseline value, and duration of prior GC use ( $<12$ vs $\geq 12$ months) as covariates $\mathrm{N}=$ no. of subjects enrolled in substudy; $\mathrm{n}=$ no. of subjects with observed data $\mathrm{p}$-value for treatment difference: ${ }^{*} p<0.05 ; \uparrow p \leq 0.001$ 

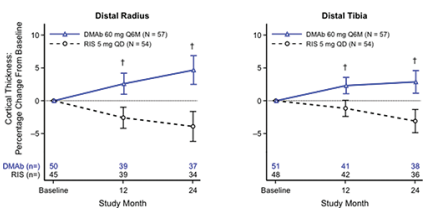

Conclusion: Compared with RIS, DMAb was associated with sustained improvements in cortical bone structure, assessed by HR-pQCT of the radius and tibia. It remains to be confirmed whether increased cortical thickness with DMAb is associated with improved bone strength in GIOP. These results further support DMAb as a treatment for GC-treated patients at increased fracture risk.

\section{REFERENCES:}

[1] Saag KG, et al. Lancet Diabetes Endocrinol. 2018;6(6)

[2] Saag KG, et al. Ann Rheum Dis. 2018;77 (Suppl 2)

Acknowledgement: This study was funded by Amgen Inc.

Disclosure of Interests: Piet Geusens Grant/research support from: Research support, consultant and/or speaker fees from: Pfizer, Abbott, Eli Lilly, Amgen, MSD, Roche, UCB, BMS, Novartis, Will-Pharma, Grant/research support from: Pfizer, Abbott, Lilly, Amgen, MSD, Will, Bio Minerals and Roche, Consultant for: Research support, consultant and/or speaker fees from: Pfizer, Abbott, Eli Lilly, Amgen, MSD, Roche, UCB, BMS, Novartis, Will-Pharma, Speakers bureau: Research support, consultant and/or speaker fees from: Pfizer, Abbott, Eli Lilly, Amgen, MSD, Roche, UCB, BMS, Novartis, Will-Pharma, Speakers bureau: Pfizer, Abbott, Lilly, Amgen, MSD, Will, Bio Minerals and Roche, Stefan Goemaere Grant/research support from: Grants/research funding from Amgen, UCB., Speakers bureau: Speakers' bureau for Amgen., Nicola Pannacciulli Shareholder of: Amgen Inc. stockholder., Employee of: Amgen Inc. employee at the time of the study., Nancy Lane Consultant for: Samumed, LLC, Eric Lespessailles Grant/ research support from: Grants/research support from Amgen, Eli Lily, MSD, UCB., Consultant for: Consultant for Amgen, Expanscience, Eli Lilly, MSD, UCB., Osvaldo Messina Consultant for: Consultant for Eli Lily, Amgen, Pfizer., Speakers bureau: Speakers' bureau for Eli Lily, Amgen, Pfizer., Roland Chapurlat Grant/ research support from: Grants/research support from Amgen, Roche-Chugai, MSD., Consultant for: Consultant for Amgen, UCB, Pfizer, Bristol-Myers Squibb, Sandoz, Radius., Speakers bureau: Speakers fees for Eli Lily, Pfizer, Abbvie, MSD, Janssen-Cilag., Xiang Yin Shareholder of: Amgen Inc. stockholder., Employee of: Amgen Inc. employee at the time of the study., Rachel Wagman Shareholder of: Amgen Inc. stockholder., Employee of: Amgen Inc. employee., Joop van den bergh Grant/research support from: Grants/research support from Eli Lily, Sanofi, Amgen.

DOI: 10.1136/annrheumdis-2019-eular.2711

\section{OP0081 \\ RELATIONSHIP BETWEEN DIFFUSE IDIOPATHIC SKELETAL HYPERSOSTOSIS AND FRAGILITY VERTEBRAL FRACTURE - A PROSPECTIVE STUDY IN OLDER MEN}

Anaïs Guiot ${ }^{1}$, Pawel Szulc ${ }^{2}$, Roland Chapurlat ${ }^{1} .{ }^{1}$ Hospital Édouard Herriot, Pavillon F, Lyon, France, ${ }^{2}$ Hospital Édouard Herriot - INSERM, Pavillon F, Lyon, France

Background: Diffuse idiopathic skeletal hyperostosis (DISH) is a common disorder of unknown cause characterized by ossifications of entheses with spinal and extraspinal manifestations(1). The prevalence ranges from $4 \%$ to $35 \%$, depending on the diagnostic criteria (2). An increased risk of vertebral fracture in DISH has been suggested, due to the loss of flexibility of the fused spine, reminiscent of what is observed in ankylosing spondylitis(3-6).

Objectives: The aim of this study was to prospectively analyze the risk of vertebral fracture in men with DISH, compared with men without DISH.

Methods: Men older than $50(n=782)$ had coronal and lateral spine radiographs along with DXA and were monitored prospectively. We analyzed the risk of incident vertebral fractures (over 7.5 years) in men with DISH defined by flowing ossification alongside the anterolateral aspect of at least four contiguous vertebral bodies, relative intervertebral disc preservation and the absence of apophyseal ankylosis and inflammatory changes of the SI joints, according to Resnick'criteria (7). Incident vertebral fracture was defined by a decrease of at least $20 \%$ or $4 \mathrm{~mm}$ in any vertebral height (anterior, central or posterior) between the follow-up and the baseline radiographs.

Results: DISH was present in $21,7 \%(170 / 782)$ of men (mean age=). Among the 782 examined at baseline, 761 had at least one spine $X$-ray after baseline and $164 / 170$ men with DISH had enough available data to be analyzed. Vertebral fracture incidence was higher in men with DISH compared with those without DISH (mean 10/164 (6.1\%) vs. 16/597 (2.7\%); p<0.05). DISH was also associated with the risk of vertebral fracture after adjustment for age, BMI, lumbar spine bone mineral density (BMD), prevalent vertebral fractures (Grade 2\&3), disc space narrowing and endplate irregularity $(\mathrm{OR}=2.89,[95 \% \mathrm{Cl}: 1.15-7.28] ; \mathrm{p}<0.05) .6 .3 \%(10 /$ 149) of men with DISH had both normal BMD $\left(\geq 0.912 \mathrm{~g} / \mathrm{cm}^{2}\right)$ and increased risk of vertebral fracture (OR 6.54 [95\% $\mathrm{Cl}: 2.13-20.26]$; $p<0.05$ ).

Conclusion: DISH is associated with higher risk of vertebral fracture, independently of BMD. The risk of vertebral fracture of men with DISH but normal BMD may be underestimated.

\section{REFERENCES:}

[1] Mader R, Verlaan J-J, Buskila D. Diffuse idiopathic skeletal hyperostosis: clinical features and pathogenic mechanisms. Nat Rev Rheumatol. 2013;9 (12):741-50.

[2] Diederichs G, Engelken F, Marshall LM, Peters K, Black DM, Issever AS et al. Diffuse idiopathic skeletal hyperostosis (DISH): relation to vertebral fractures and bone density. Osteoporos Int. juin 2011;22(6):1789-97.

[3] Ghozlani I, Ghazi M, Nouijai A, Mounach A, Rezqi A, Achemlal L, et al. Prevalence and risk factors of osteoporosis and vertebral fractures in patients with ankylosing spondylitis. Bone. mai 2009;44(5):772-6.

[4] Davey-Ranasinghe N, Deodhar A. Osteoporosis and vertebral fractures in ankylosing spondylitis. Curr Opin Rheumatol. juill 2013;25(4):509-16

[5] Leone A, Marino M, Dell'Atti C, Zecchi V, Magarelli N, Colosimo C. Spinal fractures in patients with ankylosing spondylitis. Rheumatol Int. oct 2016;36(10):1335-46.

[6] Caron T, Bransford R, Nguyen Q, Agel J, Chapman J, Bellabarba C. Spine fractures in patients with ankylosing spinal disorders. Spine. 15 mai 2010;35(11):E458-464.

[7] Resnick D, Niwayama G. Radiographic and pathologic features of spinal involvement in diffuse idiopathic skeletal hyperostosis (DISH). Radiology. juin 1976;119(3):559-68

Disclosure of Interests: None declared

DOI: 10.1136/annrheumdis-2019-eular.4374

\section{OP0082 TEMPORAL TRENDS OF BISPHOSPHONATE DISCONTINUATION AND FACTORS ASSOCIATED WITH ALENDRONATE DISCONTINUATION AND RESTART AT POPULATION LEVEL}

Giovanni Adami $^{1,2}$, Ayesha Jaleel ${ }^{3}$, Jeffrey Curtis ${ }^{1}$, Rui Chen ${ }^{1}$, Huifeng Yun ${ }^{1}$, Shanette Daigle ${ }^{1}$, Tarun Arora ${ }^{1}$, Maria Danila ${ }^{1}$, Nicole Wright ${ }^{1}$,

Suzanne Cadarette ${ }^{4}$, Amy Mudano ${ }^{1}$, Jeff Foster ${ }^{1}$, Kenneth Saag ${ }^{1}$. ${ }^{1}$ University of Alabama at Birmingham, Birmingham, United States of America; ${ }^{2}$ University of Verona, Rheumatology Unit, Verona, Italy, ${ }^{3}$ Baptist Brookwood Hospital, Birmingham, United States of America; ${ }^{4}$ University of Toronto, Toronto, Canada

Background: Bisphosphonates are the most commonly used class of osteoporosis medication worldwide. Rare adverse events related to long-term use of bisphosphonates have raised interest in planned temporary drug discontinuation. Due to chronicity of osteoporosis, restarting osteoporosis medication is likely to be needed after such a discontinuation. Trends in the discontinuation and the restart of bisphosphonates and their reasons are not fully understood.

Objectives: We investigated the temporal trends of bisphosphonate discontinuation from 2010 to 2015 and evaluated the factors associated with alendronate only discontinuation and restart of any osteoporosis medication at a population level.

Methods: To determine the temporal trends of discontinuation (at least 12 months without prescription claims) from 2010 to 2015, we identified a cohort of women with long-term bisphosphonate therapy (medication possession ratio (MPR) $\geq 80 \%$ for at least 3 continuous years) derived from the enhanced $5 \%$ Medicare sample and a cohort of beneficiaries with evidence of osteoporosis (defined using diagnosis and fracture codes, and medication claims). We used a casecrossover design, nested within the cohort study, to identify factors associated with discontinuation of long-term alendronate therapy and restart of any osteoporosis medication. We used conditional logistic regression adjusted for potential confounders to compare factors associated with alendronate discontinuation and osteoporosis therapy restart in the hazard period (120 days) referent to the preceding control periods (120 days).

Results: We identified a total of 73,800 women with exclusive long-term alendronate $(59,251)$, risedronate $(6,806)$, or zoledronic acid $(7,743)$ use, respectively, of which 26,281 (35.6\%) women discontinued therapy. The proportion of long-term bisphosphonate users who discontinued therapy increased from 1.7\% in 2010 to $14.0 \%$ in 2012, and remained relatively stable thereafter (Figure 1). After adjustment, factors most strongly associated with the discontinuation of alendronate included: a new prescription of benzodiazepines (adjusted Odds Ratio [aOR] = $2.5,95 \% \mathrm{Cl}[2.1,3.0])$, prior dual-energy X-ray absorptiometry (DXA) scan (aOR = $1.8,95 \% \mathrm{Cl}[1.7,2.0])$, skilled nursing facility care utilization $(\mathrm{aOR}=1.8,95 \% \mathrm{Cl}$ $[1.6,2.1])$. Factors most strongly associated with the restart of any osteoporosis 